\title{
Biotic vs. abiotic Earth: A model for mantle hydration and continental coverage
}

\author{
Dennis Höning ${ }^{\mathrm{a}, *}$, Hendrik Hansen-Goos ${ }^{\mathrm{a}}$, Alessandro Airo ${ }^{\mathrm{b}}$, Tilman Spohn ${ }^{\mathrm{a}, \mathrm{c}}$ \\ ${ }^{a}$ German Aerospace Center (DLR), Institute of Planetary Research, Rutherfordstr. 2, 12489 Berlin, Germany \\ ${ }^{\mathrm{b}}$ Free University Berlin, Institute of Geological Sciences, Malteserstr. 74-100, 12249 Berlin, Germany \\ c University of Münster, Institute of Planetology, Wilhelm-Klemm-Str. 10, 48149 Münster, Germany
}

\section{A R T I C L E I N F O}

Article history:

Received 12 March 2013

Received in revised form 14 October 2013

Accepted 16 October 2013

Available online 25 October 2013

Keywords:

Plate tectonics

Global water cycle

Astrobiology

Life

Continental growth

Biological weathering

\begin{abstract}
A B S T R A C T
The origin and evolution of life has undoubtedly had a major impact on the evolution of Earth's oceans and atmosphere. Recent studies have suggested that bioactivity may have had an even deeper impact and may have caused a change in the redox-state of the mantle and provided a path for the formation of continents. We here present a numerical model that assumes that bioactivity increases the continental weathering rate and that relates the sedimentation rate to the growth of continents and to the hydration of the mantle using elements of plate tectonics and mantle convection. The link between these factors is provided by assuming that an increase of the thickness of the sedimentary layer of low permeability on top of a subducting oceanic slab will reduce its dewatering upon subduction. This in turn leads to a greater availability of water in the source region of andesitic partial melt, resulting in an enhanced rate of continental crust production, and to an increased regassing rate of the mantle. The mantle in turn responds by reducing the mantle viscosity while increasing the convective circulation rate, degassing rate and plate speed. We use parameters that are observed for the present Earth and gauge uncertain parameters such that the present day continental surface area and mantle water concentration can be obtained. Our steady state results show two stable fixed points in a phase plane defined by the fractional continental surface area and the water concentration in the mantle, one of them pertaining to a wet mantle and the continental surface area of the present day Earth, and the other to a dry mantle and a small continental surface area. When the sedimentation rate is reduced, both fixed points move and the area of attraction of the latter fixed point increases systematically. We conclude that if the presence of life has increased the continental weathering rate, as is widely believed, and led to the observables of a wet mantle and a continental surface coverage of roughly $40 \%$, an abiotic Earth would likely have evolved toward a dry mantle with a small continental surface area instead.
\end{abstract}

(c) 2013 Elsevier Ltd. All rights reserved.

\section{Introduction}

It is widely accepted that life has greatly affected various aspects of Earth's evolution, in particular the chemistry of the atmosphere and oceans (e.g. Kasting, 1993). The interplay between photosynthetic carbon fixation and respiration does not only control the carbon cycle but also had a role in causing the great oxidation event (Holland, 2006), which in turn might have triggered snowball Earth events (Knopp et al., 2005). An influence of the biosphere on the Earth's interior is much less certain.

A general model that does not include specific interactions between the biosphere and the internal evolution of the Earth has been put forward by Kleidon (2010). Based on the fact that the

\footnotetext{
* Corresponding author. Tel.: +49 30670557905.

E-mail addresses: dennis.hoening@dlr.de (D. Höning), hendrik.hansen-goos@dlr.de (H. Hansen-Goos),

alessandro.airo@fu-berlin.de (A. Airo), tilman.spohn@dlr.de (T. Spohn).
}

biosphere harvests solar energy through photosynthesis, he suggested that life holds many reservoirs on the Earth far away from the thermodynamic equilibrium. It has further been suggested that the formation of continents may be a consequence of bioactivity and that the potential energy stored in the continents may have been derived from solar energy harvested by microorganisms and converted into chemical energy by the geodynamic engine (Rosing et al., 2006). These authors substantiate their hypothesis by referring to the putative temporal coincidence of the origin of life and the growth of continents. Indeed, products of biologically enhanced continental weathering can influence the processes at subduction zones, particularly if they contain volatiles, and the subduction of sediments is known to impact the chemical fluxes into the mantle and the chemical composition of partial melt (e.g. Plank and Langmuir, 1998; Sleep et al., 2012). The colonization of the continents by prokaryotic microorganisms and later by multicellular eukaryotes (Schwartzman and Volk, 1989), such as land plants (Drever, 1994) and fungi (Hoffland et al., 2004) is believed 
to have increased the rate of continental weathering, which presumably has increased the amount of sediments deposited in the deep-ocean trenches. A thicker sedimentary layer would not only increase the amount of water being subducted but, as we will discuss later in this paper, would also reduce the rate of shallow dewatering due to overlying and interbedded sediments of low permeability (e.g. clay-rich deposits) sealing off the oceanic crust.

The flux of volatiles (mainly water and carbon dioxide) into the mantle is of particular interest since it is well known that volatiles reduce the activation energy for creep in the mantle and thereby the effective mantle viscosity. By reducing the melting temperature, subducting volatiles also increase the rate of partial melt formation (Blacic, 1972). Particularly water has been found to be essential for the formation of granite (Campbell and Taylor, 1983). Carbon dioxide can enter into the mantle via the subduction of biomass and carbonates. Carbonates can be formed through biologically-induced mineralization occurring on the benthos of the continental shelfs (e.g., coral reefs or microbialites) and subsequently eroded and transported into the deep-ocean, or more recently, may have a planctonic origin (e.g. Coccolitophores) and form pelagic sediments on the seafloor that are eventually subducted. Water enters subduction zones mainly as seawater in the porous upper oceanic crust, as structural water (e.g., in serpentinites and amphibolites) or as pore water in sediments (e.g., in porous sandstones). Lithologic studies have shown that around $10 \%$ of the sediments in subduction zones are subducted and initially contain up to $40 \%$ per mass water (Rea and Ruff, 1996).

On average $60 \%$ of water entering a subduction zone is contained within the pore space of the sedimentary layer and fractures of the oceanic crust (Jarrard, 2003), while the rest is bound as structural water within the minerals itself. During the first few kilometers of subduction (Fig. 1(I)), pore and loosely bound water is partially expelled. Seismic reflection observations (e.g. Shipley and Moore, 1986) indicate that half of the pore water contained in the lower part of the sedimentary layer is expelled during the first $4 \mathrm{~km}$ of subduction. In contrast, Shipley and Moore (1986) were unable to resolve a dewatering of the upper, clay-rich part which mainly comes from the adjacent continental crust. Because of its low permeability, this layer may seal the underlying sediments and porous oceanic crust against further dewatering. However, Fisher and Byrne (1990) have described mineralized fractures present in once subducted sediments, indicating some fluid migration. It has further been argued (Byerlee, 1993; Fisher

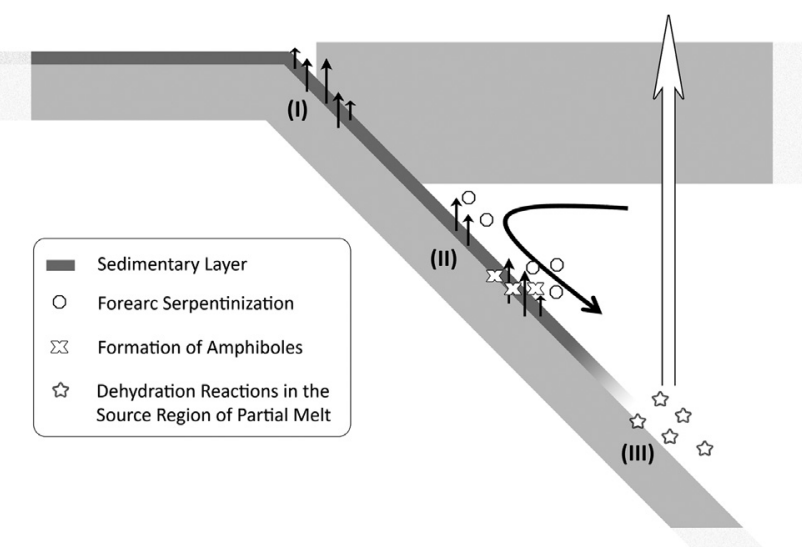

Fig. 1. Schematic cartoon of various fluid-related processes in a subduction zone, down to the source region of partial melt. (I) Shallow dewatering of sediments and the porous oceanic crust due to compaction and bending. The clay-rich section of the sedimentary layer partially suppresses dewatering. (II) Dehydration by metamorphic reactions of oceanic crust and sediments. Peridotite serpentinites form in the forearc mantle and are dragged downward by induced convection. (III) Dehydration of hydrous minerals (e.g. amphibolites and serpentinites) leads to partial melting. et al., 1995), that seismic events may trigger the interconnection of these fluid reservoirs, facilitating a partial escape of water. Water also may migrate laterally within the lower section (e.g. Shipley and Moore, 1986), or may be stored in hydrous minerals formed during low-temperature metamorphism (e.g. Jarrard, 2003; Stern, 2002). Nevertheless, the permeability of the clay-rich sedimentary layer decreases with increasing lithostatic pressure and compaction. With increasing depth, the sedimentary layer acts as an increasingly effective barrier to dewatering (e.g. Shipley and Moore, 1986; Moore, 1987). Note that the permeability we use in the model to describe the flow of water through the sedimentary layer in this region is a macro-scale representative permeability. The thickness of the sedimentary layer is an important parameter for the capability of the slab to retain a portion of its original pore water to be transported with the subducting slab to a depth below the Moho (depth $>30 \mathrm{~km}$ ).

With pressure and temperature increasing further, the subducting slab dehydrates continuously due to metamorphic reactions (Fig. 1(II)). In particular, the formation of blueschist (and, at greater depth, amphibolite) out of hydrous basalts releases significant amounts of water. Also, the sediments can undergo metamorphic dehydration reactions, although the amount of released water depends greatly on the mineralogical composition of the detritus. Hydrous melting leads to the formation of veins (e.g. Sheng et al., 2013) suggesting a partial loss of water through fractures despite the impermeable layer. Sediments can even melt and the sedimentary layer may detach from the subducting slab (Currie et al., 2007). Consequently, the sedimentary layer can no longer be treated as an impermeable barrier. Any water that is not bound to hydrous minerals such as amphiboles will be released to the forearc mantle. This water, however, will react with peridotite forming serpentinites and will remain temporarily in the forearc mantle (Scambelluri and Tonarini, 2012; Hyndman and Peacock, 2003; Hattori and Guillot, 2003). Because convection induced by the subducting slab will drag the forearc mantle to greater depth, the expelled water from the subducting crust and sediments in this section (Fig. 1(II)) will not be entirely lost.

Water enters the source region of andesite partial melt (Fig. 1 (III)) where it will be released due to the breakdown of the minerals mainly as water bound in amphiboles and serpentinites that formed either at mid-ocean ridges, in the oceanic crust during subduction, or in the forearc mantle (e.g. Hattori and Guillot, 2003; Guillot and Hattori, 2013). In the latter two cases, a sedimentary layer of low permeability acts to increase the formation rate of these minerals as it partially suppresses dewatering at very shallow depth.

In summary, although the details of the water budget and its recycling in the subduction zone are complex, a simple relation between the thickness of the sediment cover and the rate of shallow dewatering and therefore the rate of water transfer into the mantle seems to be justified, at least for the modeling approach presented in this paper. We employ a parameterized numerical model which includes mantle convection, continental crust production and erosion as well as mantle water regassing and outgassing, in order to study whether present day Earth would be different without an active biosphere. Our focus is on finding possible steady states for the continental surface area and the mantle water concentration. We investigate the neighborhood of these steady states to determine their zones of attraction. We gauge our model to the present Earth with its observed mantle water concentration and continental surface coverage and then systematically vary the sedimentation rate along with other parameters.

\section{Model}

In the following section, we present the equations used to calculate the regassing and outgassing rates of the mantle and the 


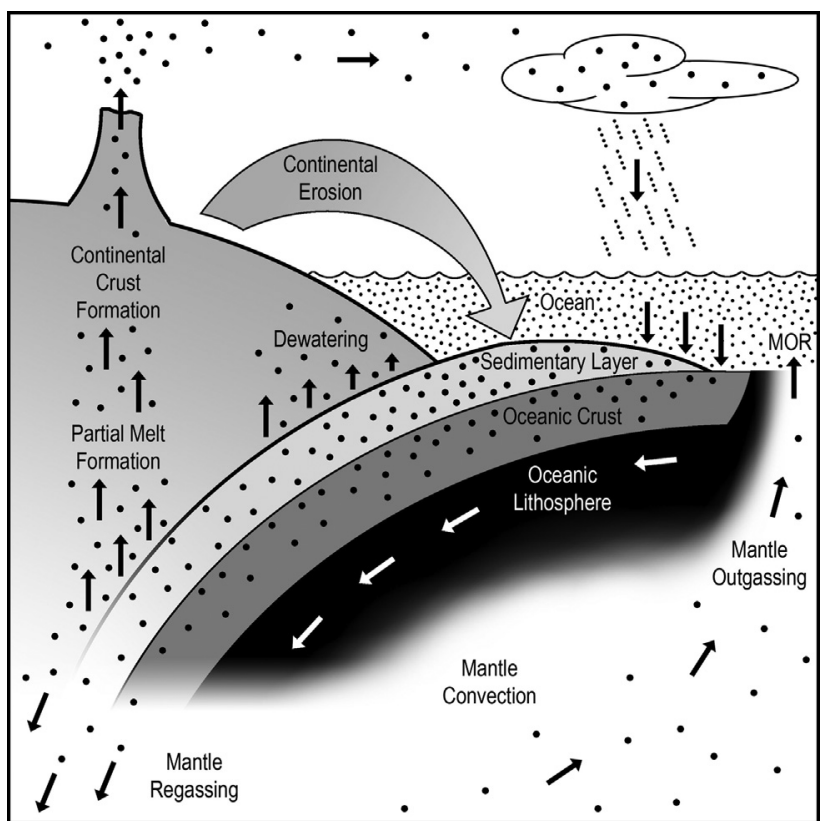

Fig. 2. Schematic cartoon depicting Earth's global water cycle, where water is represented by large and small dots, its path by black arrows, and movement of the oceanic plate by white arrows. Initial water uptake occurs within the submarine oceanic crust and sediments. Water loss first occurs after the subduction trench through dewatering, followed by the formation of the water-rich partial melt. The partial melt drives arc volcanism and continental crust formation. However, a fraction of the water contained in the subducting plate is regassed into the mantle. The water leaves the convecting mantle at mid oceanic ridges (MOR) as free volatiles or becomes part of the newly formed oceanic crust.

continental production and erosion rates. Cartoons of the model are shown in Figs. 1 and 2.

\subsection{Continental erosion and input of water and sediments into subduction zones}

The rate of continental erosion $\dot{A}_{c, e}$ (with the amount of eroded sediments $A_{c, e}$ ) is set proportional to the continental area $A_{c}$ itself

$\dot{A}_{c, e}=A_{c} \tau^{-1}$

with the erosion time $\tau$. As we are interested in steady state results, the eroded sediments are assumed to accumulate instantaneously along the continental margins with the total length $L_{c}$ and subduct with the underlying oceanic lithosphere. Hence, the thickness of the subducting sedimentary layer $d_{\text {sed }}$ can be approximated by

$d_{\text {sed }}=\frac{\varsigma A_{c} h_{c}}{L_{c} v_{\text {subd }} \tau}$,

where $v_{\text {subd }}$ is the subduction velocity, $h_{c}$ is the average height of continents and $\varsigma$ is a constant. To determine the length of continental margins, we assume randomly distributed spherical caps as continents which may overlap. From stochastic geometry (Schneider and Weil, 2008) we find

$\frac{L_{c}}{R_{E}}=4 \pi n(1-x) \sqrt{\left(\frac{1}{n} \ln \left[\frac{1}{1-x}\right]\right)-\left(\frac{1}{n} \ln \left[\frac{1}{1-x}\right]\right)^{2}}$,

where $R_{E}$ is the radius of the Earth, $n$ is the number of continents and $x=A_{c} / A_{\text {surf }}$ is the relative surface area covered with continents $\left(A_{\text {surf }}\right.$ is the total surface of the Earth). $L_{c}$ has its maximum for $x \approx 0.4$, which corresponds to the continental area of the present day Earth, and suggests that present day Earth may have maximized the length of its continental margins. We assume that the total length of ocean-continent subduction zones $S_{o c}$ is proportional to the length of continental margins, i.e. $S_{o c}=c L_{c}$.

From the observed present day total length of subduction zones of $5.5 \times 10^{7} \mathrm{~m}$ (Stern, 2002) we find $c \approx 0.9$. On present Earth, active and passive margins are about equally frequent $(c \approx 0.5)$. The deviation is a consequence of assuming spherical caps rather than actual continental shapes.

The total length of convergent plate boundaries $S_{\text {tot }}$ is assumed to always remain constant. Although small parts of the convergent plate boundaries of present day Earth are probably of the oceanocean type (e.g. the Philippine Plate subducting beneath the Pacific Plate), we assume $S_{o c}=S_{t o t}$ for present day Earth. As the continental surface area in the model decreases below its present day value $\left(A_{c}<A_{c}\left(L_{c, \text { max }}\right)\right)$ we have $S_{o c}<S_{\text {tot }}$; the difference being accounted for by ocean-ocean subduction zones with a total length of $S_{o o}=S_{t o t}-S_{o c}$. Whenever the continental surface area exceeds its present day value $\left(A_{c} \geq A_{c}\left(L_{c, \max }\right)\right)$ we use $S_{o o}=0$. In this case, the resulting difference between $S_{o c}$ and $S_{\text {tot }}$ can be attributed to convergent plate boundaries of the continent-continent type (e.g. India-Asia collision).

A large fraction of water which enters subduction zones is contained in the porous oceanic crust (e.g. Johnson and Pruis, 2003), in sediments and in hydrated minerals like serpentinites and amphibolites formed at mid-ocean ridges. In our model, we distinguish between free water $w_{s, f r e e}$, which can be expelled during shallow subduction above the Moho, and bound water $w_{s, \text { bound }}$, which cannot be expelled at this shallow depth, being, for instance, bound in minerals. We use the subscript $s$ for water which enters subduction zones. For the rate of water input we use the notation $\dot{w}_{s}$. At ocean-ocean subduction zones, we neglect the input of free water $\dot{w}_{s, f r e e}$ because the amount of subducted sediments, which could suppress shallow dewatering of the underlying oceanic crust, is negligible in these regions. Hence the input of bound water can be described by

$\dot{w}_{s, \text { bound }}=(1-\xi) W v_{\text {subd }}\left(S_{o c}+S_{o o}\right)$,

where $W$ is the water content of the oceanic crust per unit area and

$\xi=\frac{\dot{w}_{s, f r e e}}{\dot{w}_{S}}$,

with $\dot{w}_{s}=\dot{w}_{s, \text { free }}+\dot{w}_{s, \text { bound }}$. In addition to the input of bound water, at ocean-continent subduction zones the input of free water is calculated by

$\dot{w}_{s, f r e e}=\xi W v_{\text {subd }} S_{o c}$.

\subsection{Shallow dewatering}

With increasing depth, increasing lithostatic pressure squeezes the free water out of the subducting oceanic crust through the overlying sedimentary layer of low permeability. We restrict the shallow dewatering to the amount of water expelled above the Moho (Fig. 1(I)), because this water cannot contribute to a serpentinization of the forearc mantle. Following Darcy's law, the total water flow $\Delta Q$ (in mass per time) for a given length interval $\Delta l$ at each depth is determined by

$\frac{\Delta Q}{\Delta l}=S_{o c} \times \frac{\rho_{\mathrm{H}_{2} \mathrm{O}}}{\eta_{\mathrm{H}_{2} \mathrm{O}}} \times \frac{K p_{\text {lith }}}{d_{\text {sed }}}$,

where $\rho_{\mathrm{H}_{2} \mathrm{O}}$ and $\eta_{\mathrm{H}_{2} \mathrm{O}}$ are the density and the viscosity of water, respectively. The lithostatic pressure is $p_{\text {lith }}=\rho_{c} g z$ with the averaged continental density $\rho_{c}$, the gravitational acceleration $g$ and the depth $z$. The permeability $K$ is pressure dependent

$K=K_{0}\left[1-\left(\frac{P_{e}}{P_{1}}\right)^{m}\right]^{3}$ for $P_{e}<P_{1}$, 
assuming a cubic law as suggested by Kwon et al. (2004). Here, $K_{0}$ is the reference permeability, $P_{e}$ is the effective pressure, $P_{1}$ is the reference pressure and $m$ is a constant (Table 1 ). In our model, we set $P_{e}$ proportional to $P_{\text {lith }}$. For $P_{e} \geq P_{1}$ (which in our model occurs at a depth of roughly $2 \mathrm{~km}$ ), we set the permeability to zero, therefore no dewatering can occur anymore. Note that we neglect fractures which may form above the Moho, although they may lead to a partial escape of water (e.g. Fisher et al., 1995). However, since we gauge the reference permeability to the regassing rate of the present day Earth (Section 2.5), this simplification is justified. The water which remains is subducted below the Moho. Therefore, it will either be bound in stable minerals and transported further downward, or released to the forearc mantle, bound in serpentinites and dragged further down. Note that additional mechanisms, such as downward pumping (Faccenda et al., 2009), can possibly enhance the transport of water to greater depth.

\subsection{Continental production and mantle regassing}

At a depth of roughly $100 \mathrm{~km}$, most hydrated minerals (mainly amphibolite, e.g. Liu et al. (1996)) become unstable. The released water comes into contact with the surrounding mantle thereby reducing the melting temperature of the latter. Partial melting occurs, leading to surface volcanism, and new continental crust is formed as a consequence (Tatsumi and Eggins, 1995). However, not all the subducted water is consumed during partial melting, because the solidus temperature increases with increasing depth and with decreasing water concentration. Therefore, part of the water is always subducted below the region of partial melt and therefore regassed into the mantle (Hirschmann and Kohlstedt, 2012; Parai and Mukhopadhyay, 2012). Because the amount of water which has been consumed during partial melting strongly depends on the mineralogy and varies laterally, we use the simple approach that a constant fraction $\Psi$ of water which remains in the source region of partial melt is consumed during partial melting, and the rest is regassed into the mantle. Furthermore, the amount of newly formed continental crust is modeled to depend linearly on the amount of water which is consumed during partial melting. We obtain the continental production rate (Eq. (9)) and the mantle regassing rate (Eq. (10)) as

$\dot{A}_{c, p r o d}(t)=\Psi k \dot{\theta}(t)$

and

$\dot{w}_{m, \text { regas }}(t)=(1-\Psi) \dot{\theta}(t)$ respectively, where $k$ is a constant and $t$ denotes time. The rate of water $\dot{\theta}(t)$ introduced into the source region of partial melt is calculated from

$\dot{\theta}(t)=\frac{v_{\text {subd }}(t)}{v_{\text {subd }}\left(t_{0}\right)} \dot{w}_{s, \text { bound }}\left(t_{0}\right)+\max \left\{0, \frac{v_{\text {subd }}(t)}{v_{\text {subd }}\left(t_{0}\right)} \dot{w}_{\text {sfree }}\left(t_{0}\right)-v_{\text {subd }}(t) \int_{t_{0}}^{t}\left(\frac{\Delta Q}{\Delta l}\right) d t^{\prime}\right\}$,

where $t_{0}$ denotes the time at which the part of the slab reaching the source region of partial melt at time $t$ has been initially subducted. The subduction angle $\gamma$ relative to the surface tangent is taken to be constant. To determine $(\Delta Q / \Delta l)$ from Eq. (7), $S_{o c}$ and $d_{\text {sed }}$ are taken at $t=t_{0}$ while $P_{\text {lith }}$ and $K$ are taken at the depth

$z\left(t^{\prime}\right)=\sin (\gamma) \int_{t_{0}}^{t^{\prime}} v_{\text {subd }}\left(t^{\prime \prime}\right) d t^{\prime \prime}$

\subsection{Outgassing rate and mantle convection}

The water concentration in the mantle is the parameter that influences the viscosity most strongly, and therefore the mantle flow rate in our model. Following Karato and Jung (2003), we calculate the (dynamic) viscosity ratio by

$\frac{\eta}{\eta_{d r y}}=\frac{1}{1+\Phi\left(w_{m}\right)^{1.2}}$

where $w_{m}$ is the mantle water concentration (in ppm) and

$\Phi=\chi e^{(\Delta E+p \Delta V) / R T}$

Here, $\Delta E$ denotes the difference in activation energy between dry (water-free) and wet (water-rich) conditions, $\Delta V$ is the difference in activation volume between dry and wet conditions, $p$ is the pressure, $T$ is the temperature, $R$ is the gas constant, and $\chi$ is a constant (which is equivalent to the ratio of $A_{w}$ and $A_{d}$ in Karato and Jung, 2003). Note that our model does not include the effect of mantle viscosity variation on the mantle temperature. Furthermore, $p$ and $T$ change with depth. To obtain a global value for the relative mantle viscosity, we use a constant reference depth of $200 \mathrm{~km}$. The error resulting from this assumption is small. On the one hand, both pressure and temperature increase with depth, therefore the exponent in Eq. (14) changes less than these values themselves. On the other hand we use the relative mantle viscosity $\eta / \eta_{d r y}$, therefore a systematic error in the absolute values largely cancels out. Using values of Table 1 and $T_{(z=200 \mathrm{~km})} \approx 1650 \mathrm{~K}$ and $p_{(z=200 \mathrm{~km})} \approx 5.9 \mathrm{GPa}$, we obtain

Table 1

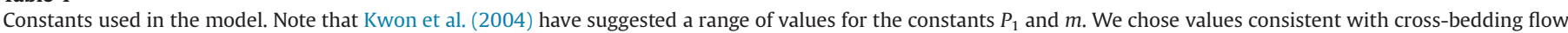

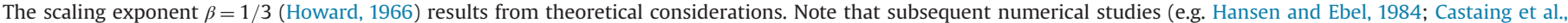
1989) have shown that $\beta$ varies depending on the convection pattern. $\beta=1 / 3$ can be considered as a maximum value.

\begin{tabular}{|c|c|c|c|}
\hline$h_{c}$ & Continental height (average) & $3.5 \times 10^{4} \mathrm{~m}$ & \\
\hline$\rho_{c}$ & Continental density (average) & $2.7 \times 10^{3} \mathrm{~kg} \mathrm{~m}^{-3}$ & \\
\hline$R_{e}$ & Radius of the Earth & $6.37 \times 10^{6} \mathrm{~m}$ & \\
\hline$n$ & Number of continents & 7 & \\
\hline$W$ & Water concentration of the oceanic crust & $3.6 \times 10^{5} \mathrm{~kg} \mathrm{~m}^{-2}$ & Carlson (2003) \\
\hline$\rho_{\mathrm{H}_{2} \mathrm{O}}$ & Density of water & $10^{3} \mathrm{~kg} \mathrm{~m}^{-3}$ & \\
\hline$\eta_{\mathrm{H}_{2} \mathrm{O}}$ & Viscosity of water & $10^{-3}$ Pa s & \\
\hline$g$ & Gravitation acceleration & $9.81 \mathrm{~m} \mathrm{~s}^{-2}$ & \\
\hline$P_{1}$ & Reference pressure, Eq. (8) & $2.5 \times 10^{7} \mathrm{~Pa}$ & Kwon et al. (2004) \\
\hline$m$ & Constant, Eq. (8) & 0.5 & Kwon et al. (2004) \\
\hline$R$ & Universal gas constant & $8.314 \mathrm{~J} \mathrm{~mol}^{-1} \mathrm{~K}^{-1}$ & \\
\hline$\beta$ & Scaling exponent & $1 / 3$ & Howard (1966) \\
\hline$\chi$ & Constant, Eq. (14) & $2.9 \times 10^{-6}$ & Karato and Jung (2003) \\
\hline$\Delta E$ & Diff. of activation energy (dry-wet) & $10^{5} \mathrm{~J} \mathrm{~mol}^{-1}$ & Karato and Jung (2003) \\
\hline$\Delta V$ & Diff. of activation volume (dry-wet) & $3 \times 10^{-6} \mathrm{~m}^{3} \mathrm{~mol}^{-1}$ & Karato and Jung (2003) \\
\hline$\gamma$ & Angle of subduction & $45^{\circ}$ & \\
\hline
\end{tabular}


Table 2

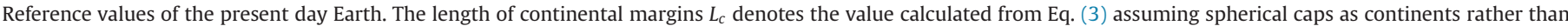

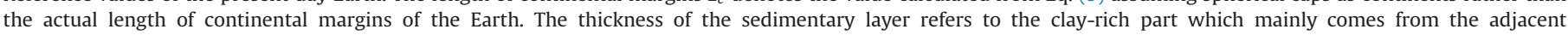
continental crust.

\begin{tabular}{|c|c|c|c|}
\hline$A_{c}$ & Continental surface area & $2 \times 10^{14} \mathrm{~m}^{2}$ & \\
\hline$d_{\text {sed }}$ & Thickness of the sedimentary layer & $50 \mathrm{~m}$ & \\
\hline$v_{\text {subd }}$ & Subduction velocity & $5 \times 10^{-2} \mathrm{~m} \mathrm{yr}^{-1}$ & \\
\hline$x$ & Relative continental surface area & 0.4 & \\
\hline$\dot{V}_{c, e}$ & Continental erosion rate & $1.5 \times 10^{9} \mathrm{~m}^{3} \mathrm{yr}^{-1}$ & Huene and Scholl (1991) \\
\hline$\dot{W}_{m, \text { regas }}$ & Mantle regassing rate & $6.3 \times 10^{-8} \mathrm{ppm} \mathrm{yr}^{-1}$ & Parai and Mukhopadhyay (2012) \\
\hline$S_{\text {tot }}$ & Total length of subduction zones & $5.5 \times 10^{7} \mathrm{~m}$ & Stern (2002) \\
\hline$w_{m}$ & Water concentration of the Earth's mantle & 300 ppm & \\
\hline$L_{c}$ & Length of continental margins & $5.9 \times 10^{7} \mathrm{~m}$ & Eq. (3) \\
\hline$\eta / \eta_{d r y}$ & Relative mantle viscosity & 0.066 & Eq. (13) \\
\hline
\end{tabular}

$\Phi \approx 0.015 \mathrm{ppm}^{-1.2}$. The viscosity enters the Rayleigh number

$R a=\frac{\alpha \rho_{m} g \Delta T d_{m}^{3}}{\eta \kappa}$

where the convecting mantle is characterized by its thermal expansivity $\alpha$, density $\rho_{m}$, thickness $d_{m}$ and thermal diffusivity $\kappa$. The superadiabatic temperature difference across the mantle is $\Delta T$. The boundary layer theory (e.g. Schubert et al., 2001) yields the convection velocity

$v_{\text {conv }} \sim R a^{2 \beta}$

where $\beta$ is a constant. We set the plate velocity and therefore the subduction velocity equal to the convection velocity. The outgassing rate is set proportional to the convection velocity, the mantle water concentration, and the thickness of the uprising plumes $d_{p l}$, which can be approximated - again using boundary layer theory - by

$d_{p l} \sim R a^{-\beta}$.

Combining all of the above the outgassing rate is obtained as

$\dot{w}_{m, o u t g}=a w_{m}\left(\frac{\eta}{\eta_{d r y}}\right)^{-\beta}$

where $a$ is a constant.

\subsection{Reference permeability}

We solve Eqs. (1), (9), (10) and (18) to determine the change of mantle water concentration and continental surface area with time. To this end we gauge the model parameters for the present day Earth such that the continental surface area and the mantle water concentration are in steady state for a continental surface area of $40 \%$ and an (upper) mantle water concentration of $300 \mathrm{ppm}$. We use the resulting parameters as input parameters for our model to assess the behavior of trajectories with different initial conditions in a phase plane spanned by the mantle water concentration and the continental surface area. Finally, we vary the input parameters to determine the impact of a reduced continental erosion rate and the sensitivity of the model to poorly constrained parameters of present day Earth.

We use a combined model consisting of a global, time dependent model for global parameters and a local depth- and time dependent model for the processes in the subducting slab. The global model acts as an input for the local one at the top of the subduction zone, and the local model feeds the global one as the subducting slab hydrates the mantle at depth and forms new continental crust. We discretize time in intervals of equal length and couple the depth intervals to time intervals via the subduction velocity.
We use the assumption that present day Earth is near a steady state with respect to its continental surface area (Patchett, 1992) and its mantle water concentration. Hence, we evaluate Eq. (10) for steady state (indicated by the subscript $s s$ ), where $v_{\text {subd }}$ and $d_{\text {sed }}$ are constant. In this case, we obtain $z\left(t^{\prime}\right)=\sin (\gamma) v_{\text {subd }}\left(t^{\prime}-t_{0}\right)$ from Eq. (12). The integration in Eq. (11) can now be performed analytically, which for $\dot{w}_{s, f r e e} \geq v_{\text {subd }} \int_{t_{0}}^{t}\left(\frac{\Delta Q}{\Delta l}\right) d t^{\prime}$ gives

$$
\begin{aligned}
\dot{\theta}_{s s}= & \dot{w}_{s, \text { bound }}+\dot{w}_{s, f r e e}-\frac{K_{0} S_{o c} \rho_{\mathrm{H}_{2} \mathrm{O}} \rho_{c} g}{2 \sin (\gamma) \eta_{\mathrm{H}_{2} \mathrm{O}} d_{s e d}}\left(\frac{P_{1}}{\left(\frac{P_{e}}{P_{\text {lith }}}\right) \rho_{c} g}\right)^{2} \\
& \times\left(1-\frac{2}{3 m+2}+\frac{3}{m+1}-\frac{6}{m+2}\right)
\end{aligned}
$$

where the sum of $\dot{w}_{s, \text { bound }}$ and $\dot{w}_{\text {s.free }}$ is determined using Eqs. (4) and (6). The reference permeability $K_{0}$ for the sedimentary layer is expected to range over 3 orders of magnitude, mostly depending on the clay content and flow direction (Kwon et al., 2004). Note that we focus on the upper, clay-rich section of the sedimentary layer, which mainly comes from the adjacent continents, and which is characterized by a low permeability. Small fractures are continuously formed (e.g. Fisher et al., 1995) and enhance the macro-scale permeability. To find a representative value for $K_{0}$, we require Eq. (10) to yield the correct regassing rate in steady state for present day Earth for a given $\Psi$. For the parameter values in Tables 1,2 and 4 we get $K_{0}=2.3 \times 10^{-18} \mathrm{~m}^{2}$ which is in the range of $1.2 \times 10^{-17} \mathrm{~m}^{2}$ to $5 \times 10^{-20} \mathrm{~m}^{2}$ suggested by Kwon et al. (2004). Note that changing poorly known parameters in Eq. (19), e.g. the angle of subduction, the representative thickness of the sedimentary layer of present day Earth or the constants $P_{1}$ and $m$ from Kwon et al. (2004) would lead to a modified reference permeability $K_{0}$ (Table 3 ).

We calculate the regassing, outgassing, continental erosion, and production rates for several initial conditions while keeping $K_{0}$ fixed in order to explore the phase plane spanned by the mantle water concentration and the continental surface area. To model the impact of the Earth's biosphere, we systematically reduce the continental weathering and erosion rate from the values observed for the present day Earth, while again keeping $K_{0}$ and the other model parameters constant. Finally, we vary the poorly known parameters $\xi$ and $\Psi$ (and then recalculate $K_{0}$ ) in order to test the robustness of our results.

\section{Results}

Assuming the present day continental weathering and erosion rate (Fig. 3), the dashed isoline and the solid isoline (indicating steady state for mantle water concentration and continental surface area, respectively) cross at a relative continental surface area of $40 \%$ and a mantle water concentration of $300 \mathrm{ppm}$, as a result of 
Table 3

Constants of the model resulting from gauging the model via the present day regassing rate. Note that the continental erosion time $\tau_{\text {Earth }}$ denotes the value for the biologically enhanced weathering rate of present day Earth.

\begin{tabular}{llll}
\hline$\tau_{\text {Earth }}$ & Continental erosion time & $4.8 \times 10^{9} \mathrm{yr}$ & Eq. (1) \\
$\varsigma$ & Constant & 5.4 & Eq. (2) \\
$k$ & $\begin{array}{l}\text { Continental surface area } \\
\text { production per water }\end{array}$ & $2.9 \times 10^{11} \mathrm{~m}^{2} \mathrm{ppm}^{-1}$ & Eq. (9) \\
& $\begin{array}{l}\text { consumption } \\
\text { Constant }\end{array}$ & $7.7 \times 10^{-11} \mathrm{yr}^{-1}$ & Eq. (18) \\
$K_{0}$ & Reference permeability & $2.3 \times 10^{-18} \mathrm{~m}^{2}$ & Eq. (19) \\
\hline
\end{tabular}

Table 4

Ratios used in the model.

\begin{tabular}{llll}
\hline$\xi$ & Fraction of free water in the oceanic crust & 0.7, & Eq. (5) \\
& & 0.8 & \\
$P_{e} / P_{\text {lith }}$ & Effective pore pressure/lithostatic pressure & 0.5 & Eq. (19) \\
$\Psi$ & Fraction of water consumed during partial & 0.7 & Eqs. \\
& melting & & $(9,10)$ \\
\hline
\end{tabular}

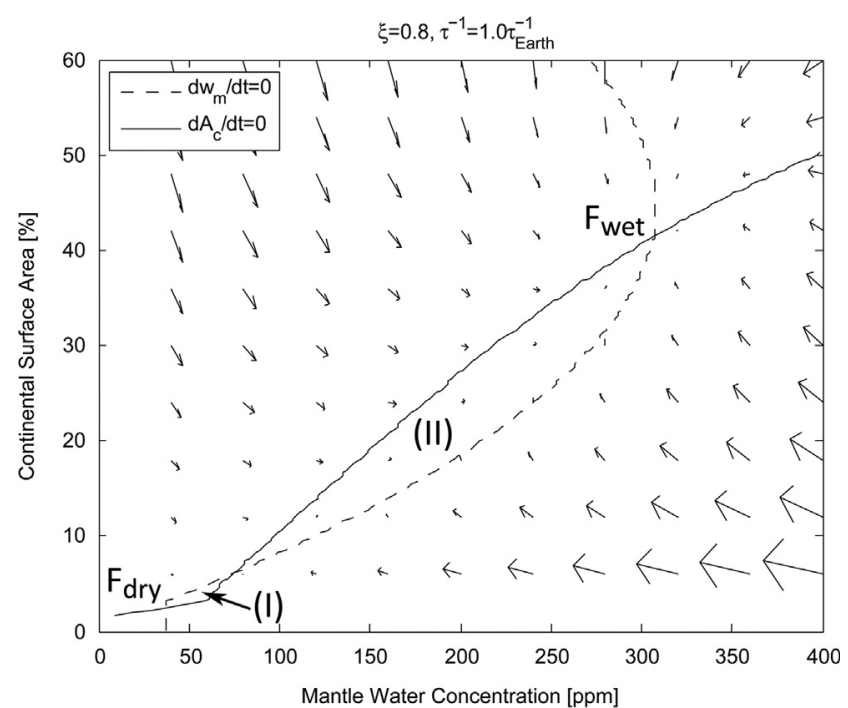

Fig. 3. Phase plane spanned by mantle water concentration and continental surface area for the present day continental erosion rate $\tau^{-1}=\tau_{E}^{-1}$. The dashed and the solid isolines indicate a steady state for mantle water concentration and the continental area, respectively. The arrows indicate state vectors for a trajectory. $\Psi=0.7$ and $\xi=0.8$. See text for further explanation.

gauging the reference permeability $K_{0}$ via the regassing rate (see Section 2.5). A state with these parameters represents a fixed point of the system $\left(F_{\text {wet }}\right)$. The directions of the state vectors (arrows) indicate that the fixed point is stable; therefore any system in the neighborhood will terminate there. This indicates that our model can explain the stability of the continental surface area and the mantle water concentration of present day Earth. There are two more equilibrium points in Fig. 3 at smaller values of continental surface coverage and mantle water concentration. The one next to $F_{\text {wet }}$ at $75 \mathrm{ppm}$ mantle water concentration and 6\% surface coverage is unstable. A small increase in water concentration, for instance, would lead to an increase in continental area which would lead to an increase in water concentration. The system would tend to move towards $F_{\text {wet }}$. The next equilibrium point $F_{d r y}$ - at a mantle water concentration of $40 \mathrm{ppm}$ and a continental surface area of $3 \%$ - is again stable. The location of $F_{d r y}$ depends on the fraction of water which enters the subduction zone bound in minerals, and therefore cannot be expelled from the oceanic crust above the Moho (considered by $\xi<1$ in the model). Therefore, a fraction of the subducting water is always regassed into the mantle, indicated by the steep slope of the dashed isoline at a mantle water concentration of $40 \mathrm{ppm}$. The mantle water concentration in steady state never falls below this value.

In the next step, we reduce the continental erosion rate to $60 \%$ of its present day value and compare in Fig. 4(a) and (b) the results for both models. When the continental erosion rate is reduced, $F_{\text {wet }}$ moves to higher values of continental surface area and smaller values of mantle water concentration. This is caused by the reduced thickness of the subducting sedimentary layer. While the value for the mantle water concentration of $F_{d r y}$ remains the same for different continental erosion rates, its value for the continental area increases with decreasing continental erosion rate. The position of the unstable fixed point is particularly important, because it determines the zones of attraction of $F_{\text {wet }}$ and $F_{d r y}$. The zone of attraction of a given fixed point is the region in the phase plane for which all trajectories starting in that region terminate in this fixed point. If a trajectory reaches or originates in area (I) (cf. Fig. 3), both the mantle water concentration and the continental area decrease with time, and $F_{d r y}$ will be reached. If, on the contrary, the trajectory reaches area (II), $F_{\text {wet }}$ will be reached instead. The zone of attraction of $F_{\text {dry }}$ increases with decreasing continental erosion rates. In summary, for a trajectory with a random starting point, biologically promoted large continental weathering and erosion rates increase the likelihood of terminating with a wet mantle and a large continental surface area.

\subsection{Variation of $\xi$}

Decreasing the proportion of water $\xi$ which can be expelled during shallow subduction by lithostatic pressure enlarges the zone of attraction of $F_{\text {wet }}$. This is due to the decrease of water loss of a subducting slab in a system with a small continental surface area. Therefore, the probability for a trajectory with a random starting point to terminate in $F_{\text {wet }}$ increases. Still, as Fig. 4(c) and (d) shows, the impact of varying the continental erosion rate remains unaffected: decreasing the continental erosion rate increases the probability for trajectories to terminate in $F_{d r y}$. In our example in Fig. 4 (c), $F_{d r y}$ even disappears for large continental erosion rates.

In the limit $\xi=1$, all the water contained in newly subducting crust can theoretically be expelled during shallow subduction. In such a case, $F_{d r y}$ moves to the origin of the graph. A planet starting without any continents would never form continents in this case, as any trajectory would run directly into the origin. This is because all water would be expelled during subduction due to the absence of a sedimentary layer. For initial starting conditions with some continental coverage, trajectories still can reach $F_{\text {wet }}$.

\subsection{Variation of $\Psi$}

Decreasing the proportion $\Psi$ of water which is consumed during partial melting also enlarges the zone of attraction of $F_{d r y}$. This is because the model is normalized to the present day mantle regassing and continental production rates. Hence, decreasing $\Psi$ forces the reference permeability in the model to higher values in order to maintain the same (present day) regassing rate. Therefore, in a system with a small continental surface area a subducting slab with a thin sedimentary layer loses most of its water during subduction, and the system terminates in $F_{d r y}$. However, a reduced continental erosion rate enhances the zone of attraction of the latter fixed point.

\subsection{Thermal evolution and speed of convergence}

The phase plane suggests possible states of a present-day Earth-like planet. Due to scaling to the present day Earth, 
a

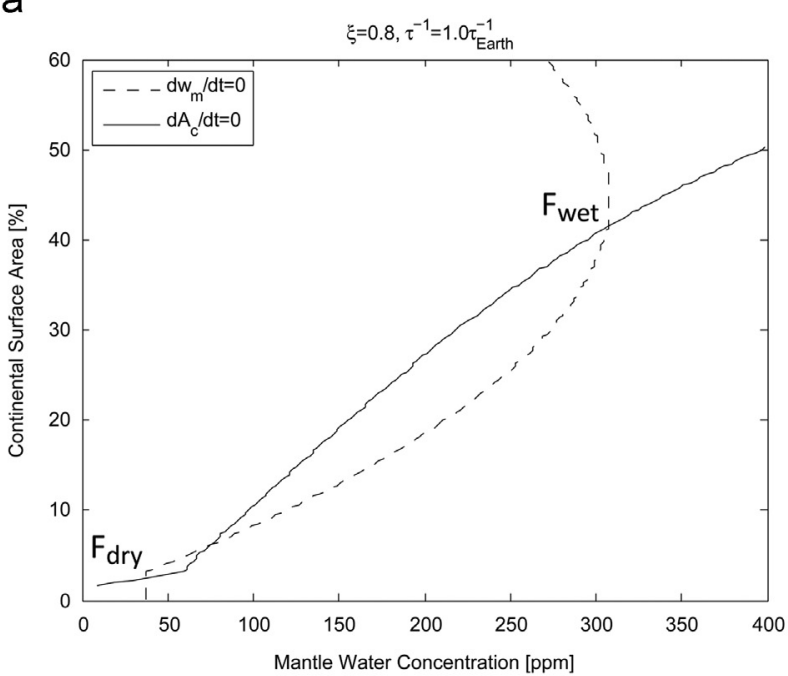

C

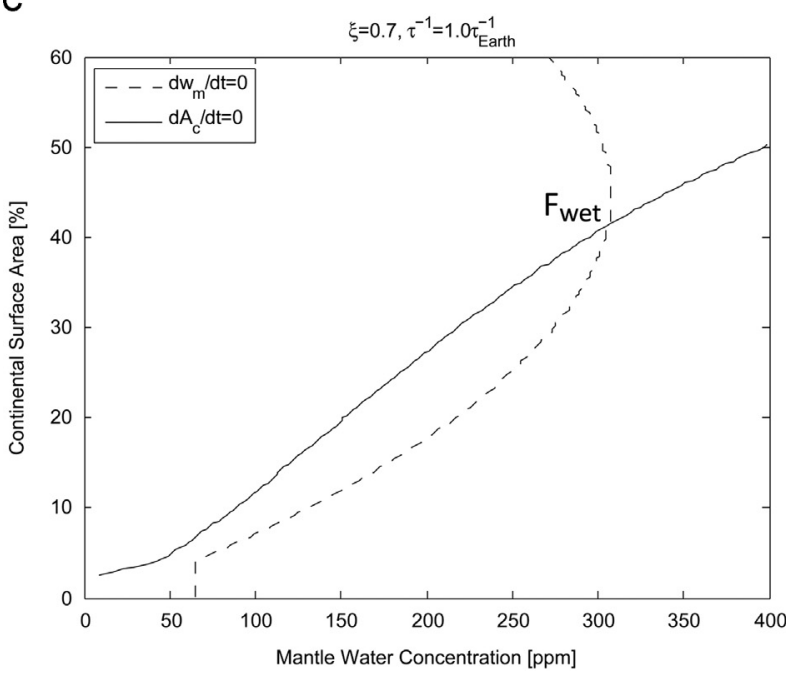

b

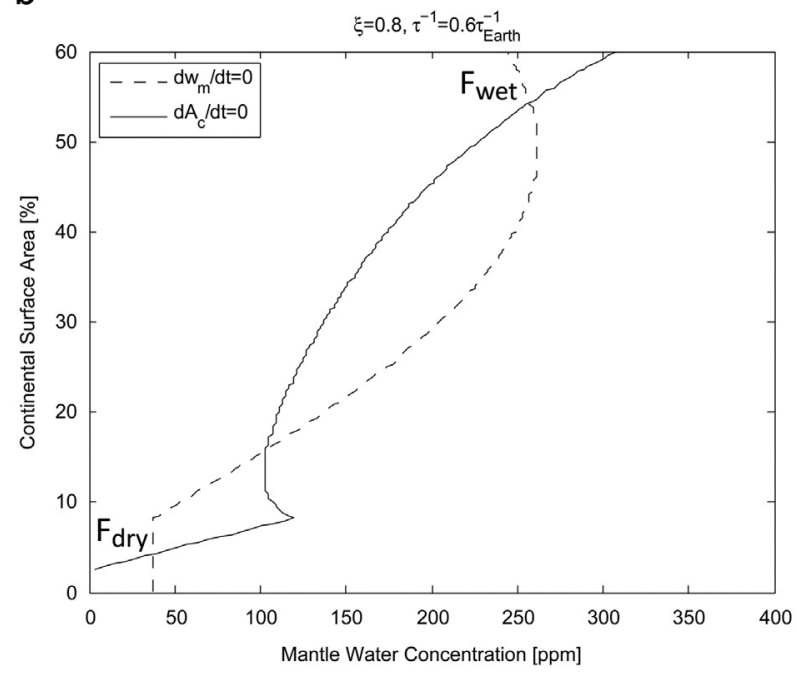

d

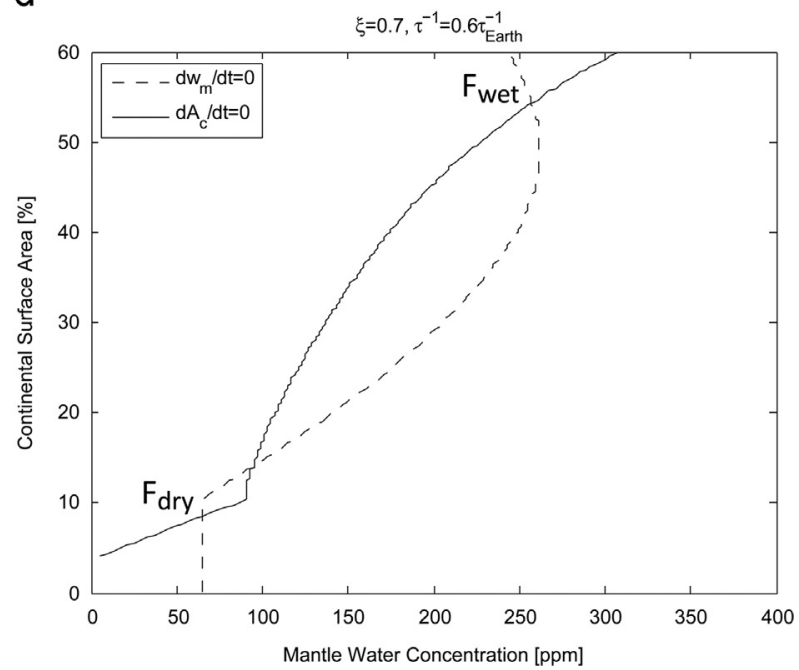

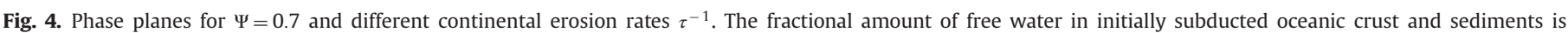

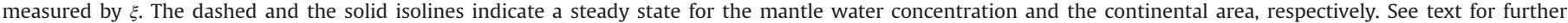
explanation.

including a thermal evolution in the model will not affect the phase plane for the present day. Therefore, we defer a thermal evolution calculation to a future study. If thermal evolution was included, the phase plane would be reshaped and fixed points would arise, disappear and move over time. A larger thermal gradient for instance as it is expected in younger planets leads to a higher degree of partial melting, which results in a higher rate of continental production. A hotter mantle enhances the Rayleigh number and therefore the speed of convection, resulting in increased regassing and outgassing rates and again in a higher rate of continental production. If the time dependent phase plane reshapes fast compared to the speed of convergence of the trajectory, a trajectory starting without continents could reach $F_{\text {wet }}$, even if the trajectory would reach $F_{d r y}$ in a static phase plane scaled to present day rates.

In our present model, the time for a typical trajectory to terminate in a fixed point exceeds the age of the Earth. This is because we refer to the present day continental production and regassing rates. Modeling the whole thermal evolution of the planet with its initially larger mantle temperature would result in faster rates of convergence. We further did not take into account subduction erosion, which is considered an important process for the destruction of continental crust (Stern, 2011). If this effect was included in our model, both the rate of continental erosion and production, and therefore the speed of convergence would increase. Still, it is possible that a planet would never reach the fixed point considering that the latter would move due to planetary cooling and that the rate of convergence is small in the vicinity of the fixed point. Near the fixed point, the regassing rate differs little from the outgassing rate, and the difference between the continental production rate and the continental erosion rate will also be small.

\section{Discussion and conclusion}

In the present study we introduce a model which couples a global model of the Earth's mantle with a local, depth dependent representation of subduction zones. Our model relates the activity of the Earth's surface biosphere to the hydration state of the mantle and to the percentage of continental coverage. We assume that life enhances continental weathering rates thereby increasing the rate at which sediments enter the trench of convergent plate boundaries. In our model we postulate that a thick sedimentary 
layer of low permeability on top of the subducting slab can suppress shallow dewatering of the latter. Without taking into account detailed metamorphic processes and water transportation pathways, the availability of larger amounts of water in the source region of andesitic partial melt entails enhanced continental production and mantle regassing rates. By implementing a parameterized mantle convection model, we are able to detect a stable fixed point for the mantle water concentration and the continental surface area which is located at the presumed present day Earth values. For decreasing continental erosion rates, the mantle water concentration in steady state decreases. Moreover, we identify a second stable fixed point in a phase plane spanned by the mantle water concentration and the continental surface area, which is located at a low continental surface area and a dry mantle. As we decrease the continental erosion rate in our model, the zone of attraction of the (present day Earth) stable fixed point with a wet mantle and large continental surface area becomes smaller. Hence, the likelihood for a planet to develop continents and to maintain a wet mantle decreases. This effect is robust, even as we modify poorly constrained model parameters.

The biologically increased production of sediments entering the subduction trench affects the evolution of the Earth in several other aspects which are not part of this study: on average, half of the water which enters subduction zones is stored in sediments (Jarrard, 2003), either as sediment pore water or as sediment structural water. Including this effect would reinforce the effect that we observe: increasing the share of free water, such as pore and loosely bound water in sediments and the porous oceanic crust, moves the fixed point corresponding to a wet mantle and large continental surface area to even higher values of both parameters. It furthermore enlarges the zone of attraction of this fixed point. An increased amount of structural water moves the fixed point with a relatively dry mantle and small continental surface area to higher values. Overall, linking the amount of sediments to the biosphere, taking into account the amount of water they contain, provides an additional mechanism which describes the importance of a biologically enhanced weathering rate for the large continental surface area and the wet mantle of present day Earth.

We are aware that effects other than the enhancement of the continental erosion rate have the potential to link the biosphere to the internal evolution of the Earth. Interestingly, a second example also pertains to the sedimentary layer on the subducting slab: during subduction, diagenetic processes of the sediments transform the soft, swollen clay mineral smectite to illite, which is much stronger and denser. As a consequence of this transformation, the permeability of the clay layers decreases (e.g. Nadeau, 2011). Laboratory experiments have shown that microbial activity can greatly promote the smectite-to-illite reaction (Kim et al., 2004; Zhang et al., 2007a, 2007b). Although microbes mainly act near the surface, we assume that their iron-reducing effect in illite-smectite minerals (Zhang et al., 2012) also enhances the conversion of smectite to illite (Eslinger et al., 1979) at greater depth as well. Due to the lower permeability of illite compared to smectite, more water is available in greater depths. In consequence, the rate of continental crust formation and mantle regassing increases. In additional numerical experiments, we included the smectite-toillite reaction using the kinetic expression by Cuadros and Linares (1996). The microbial effect was taken into account through a decrease of the kinetic activation energy of the reaction. Preliminary results suggest that including this effect enhances the difference between a biotic and an abiotic Earth even more. Compared to an abiotic scenario, the stable fixed point for the biotic Earth moves to even higher values of mantle water concentration and continental surface area. Furthermore, the zone of attraction for this fixed point widens even more, compared to the abiotic case. Like the general effect of biologically enhanced weathering which is taken into account in our present model, the biologically enhanced smectiteto-illite reaction is also suitable to increase the likelihood for the Earth to develop continents and to maintain a wet mantle.

It can be speculated that under abiotic conditions the Earth would have reached the fixed point with low continental surface area and a dry mantle. This can be viewed in the context of the evolution of continental surface area of Earth. It has been speculated that the low continental surface area on Earth during the first billion years of its evolution might correspond to the lack of an early biosphere (Rosing et al., 2006). As our results indicate, it might be possible that Earth was approaching the fixed point with small continental surface area and a dry mantle during this period and only started to evolve towards the fixed point with large continental surface area and a wet mantle with the origin of life or the evolution of metabolisms affecting global geochemistry. Note that the latter fixed point also features a maximum length of continental shelves, which are widely accepted as great habitats for early and evolved life.

The results also have implications for our ability to remotely detect the global activity of life on other planets. While it remains impossible for the foreseeable future to make in-situ observations of biomarkers on exoplanets, it might be possible to make remote measurements of the atmosphere or global surface topography in the near future. The presumably universal feature of life to create disequilibria in its surrounding environment, as it is the case for Earth's oxygen-rich atmosphere, has long been thought of as an avenue to remote life detection (Hitchcock and Lovelock, 1967). More recent studies have suggested that life's influence on weathering, erosion, sediment transport and deposition could sufficiently alter the geomorphology of planetary surfaces (e.g. braided vs. meandering river channels) to allow the remote detection of alien life (Dietrich and Perron, 2006). Sleep et al. (2012) have speculated about biosignatures in the chemistry of mantle rock and have highlighted the role that microorganisms may play for the geochemical cycles associated with plate tectonics. Other studies have suggested that a large continental surface area could be considered an indicator for an active biosphere (cf. Rosing et al., 2006), and, as our study suggests, strong volcanic activity facilitated by a low mantle viscosity, i.e. a wet mantle, might be another hint. In order to solidify this approach, further work has to address the question of whether the effects of the biosphere on the internal evolution are specific to the Earth, or if they could be treated as a proxy for life on other planets as well.

As our results suggest, biological activity promotes the hydration of the Earth's mantle. By reducing the effective viscosity of near surface layers, water plays an important role in stabilizing plate tectonics (e.g. Richards et al., 2001). Based on numerical studies, it has also been argued that an asthenosphere may help in maintaining a mobile lid (e.g. Stein and Hansen, 2008). A partially molten asthenosphere is likely the result of water (and $\mathrm{CO}_{2}$ ) reducing the solidus temperature of the mantle. In consequence, an abiotic world would be less likely to exhibit plate tectonics. If future studies support the notion that plate tectonics is significantly more likely under biotic conditions, remote data providing direct (e.g. topographic dichotomy) or indirect (e.g. magnetic field) evidence of plate tectonics on exoplanets could possibly function as a biosignature.

\section{Acknowledgement}

We are grateful to Norm Sleep for his comments which helped improve this manuscript. This work has been supported by the Helmholtz Association through the research alliance "Planetary Evolution and Life". 


\section{References}

Blacic, J.D., 1972. Effect of water on the experimental deformation of olivine. In: Heard, H.C., et al. (Eds.), Flow and Fracture of Rocks, Geophysical Monograph Series, vol. 16. AGU, Washington, D.C., pp. 109-115.

Campbell, I.H., Taylor, S.R., 1983. No water, no granites - no ocean, no continents. Geophys. Res. Lett. 10 (11), 1061-1064.

Byerlee, J., 1993. Model for episodic flow of high-pressure water in fault zones before earthquakes. Geology 21, 303-306.

Carlson, R.L., 2003. Bound water content of the lower oceanic crust estimated from modal analyses and seismic velocities of oceanic diabase and gabbro. Geophys. Res. Lett. 30 (22), 2142, http://dx.doi.org/10.1029/2003GL018213.

Castaing, B., Gunarate, G., Heslot, F., Kadanoff, L., Libchaber, A., Thomae, S., Wu, X.-Z., Zaleski, S., Zanetti, G., 1989. Scaling of hard thermal turbulence in RayleighBénard-convection. J. Fluid Mech. 204, 1-30.

Cuadros, J., Linares, J., 1996. Experimental kinetic study of the smectite-to-illite transformation. Geochim. Cosmochim. Acta 60 (3), 439-453.

Currie, C.A., Beaumont, C., Huismans, R.S., 2007. The fate of subducted sediments: a case for backarc intrusion and underplating. Geology 35 (12), 1111-1114.

Dietrich, W.E., Perron, J.T., 2006. The search for topographic signature of life. Nature 439, 411-418.

Drever, J.I., 1994. The effect of land plants on weathering rates of silicate minerals. Geochim. Cosmochim. Acta 58 (10), 2325-2332.

Eslinger, E., Highsmith, P., Albers, D., DeMayo, B., 1979. Role of iron reduction in the conversion of smectite to illite in bentonites in the disturbed belt, Montana. Clays Clay Miner. 27 (5), 327-338.

Faccenda, M., Gerya, T.V., Burlini, L., 2009. Deep slab hydration induced by bendingrelated variations in tectonic pressure. Nat. Geosci. 2, 790-793.

Fisher, D.M., Brantley, S.L., Everett, M., Dzvonik, J., 1995. Cyclic fluid flow through a regionally extensive fracture network within the Kodiak accretionary prism. J. Geophys. Res. 100 (B7), 12881-12894.

Fisher, D., Byrne, T., 1990. The Character and distribution of mineralized fractures in the kodiak formation, Alaska: implications for fluid flow in an underthrust sequence. J. Geophys. Res. 95 (B6), 9069-9080.

Guillot, S., Hattori, K., 2013. Serpentinites: essential roles in geodynamics, arc volcanism, sustainable development, and the origin of life. Elements 9, 95-98.

Hansen, U., Ebel, A., 1984. Experiments with a numerical model related to mantle convection: boundary layer behavior of small- and large scale flows. Phys. Earth Planet. Inter. 36, 374-390.

Hattori, K., Guillot, S., 2003. Volcanic fronts form as a consequence of serpentinite dehydration in the forearc mantle wedge. Geology 31 (6), 525-528.

Hirschmann, M., Kohlstedt, D., 2012. Water in Earth's mantle. Phys. Today 65 (3), 40-42.

Hitchcock, D.R., Lovelock, J.E., 1967. Life detection by atmospheric analysis. Icarus 7, 149-159.

Hoffland, E., Kuyper, T.W., Wallander, H., Plassard, C., Gorbushina, A.A.., Haselwandter, K., Holström, S., Lendeweert, R., Lundström, U.S., Rosling, A., Sen, R., Smits, M.M., van Hees, P.A.W., van Breemen, N., 2004. The role of fungi in weathering. Front. Ecol. Environ. 2 (5), 258-264.

Holland, H.D., 2006. The oxygenation of the atmosphere and oceans. Philos. Trans. R. Soc. 361, 903-915.

Howard, L.N., 1966. Convection at high Rayleigh number. In: Proceedings of the 11th International Congress on Applied Mechanics. Springer, pp. 1109-1115.

Huene, R.v., Scholl, D.W., 1991. Observations at convergent margins concerning sediment subduction, subduction erosion, and the growth of continental crust. Rev. Geophys. 29, 279-316.

Hyndman, R.D., Peacock, S.M., 2003. Serpentinization of the forearc mantle. Earth Planet. Sci. Lett. 212, 417-432.

Jarrard, R.D., 2003. Subduction fluxes of water, carbon dioxide, chlorine, and potassium. Geochem. Geophys. Geosyst. 4 (5).

Johnson, H.P., Pruis, M.J., 2003. Fluxes of fluids and heat from the oceanic crustal reservoir. Earth Planet. Sci. Lett. 216, 565-574.

Karato, S.-I., Jung, H, 2003. Effects of pressure on high-temperature dislocationcreep in olivine. Philos. Mag. 83 (3), 401-414.

Kasting, J., 1993. Earth's early atmosphere. Science 259, 920-926.

Kim, J., Dong, H., Seabaugh, J., Newell, S.W., Eberl, D.D., 2004. Role of microbes in the smectite- to illite reaction. Science 303, 830-832.
Kleidon, A., 2010. Life, hierarchy, and the thermodynamic machinery of planet Earth. Phys. Life Rev, 7, 428-460.

Knopp, R.E., Kirschvink, J.L., Hilburn, I.A., Nash, Z.N., 2005. The paleoproterozoic snowball Earth: a climate disaster triggered by the evolution of oxygenic photosynthesis. Div. Geol. Planet. Sci. 102 (32), 11131-11136.

Kwon, O., Kronenberg, A.K., Gangi, A.F., Johnson, B., Herbert, B.E., 2004. Permeability of illite-bearing shale: 1 . Anisotropy and effects of clay content and loading. J. Geophys. Res. 109, B10205, http://dx.doi.org/10.1029/2004JB003052.

Liu, J., Bohlen, S.R., Ernst, W.G., 1996. Stability of hydrous phases in subducting oceanic crust. Earth Planet. Sci. Lett. 143, 161-171.

Moore, J.C., 1987. Expulsion of fluids from depth along a subduction-zone decollement horizon. Nature 326 (23), 785-788.

Nadeau, P.H., 2011. Earth's energy "Golden Zone": a synthesis from mineralogical research. Clay Miner. 46, 1-24.

Parai, R., Mukhopadhyay, S., 2012. How large is the subducted water flux? New constraints on the regassing rates. Earth Planet. Sci. Lett. 317-318, 396-406.

Patchett, P.J., 1992. Isotopic studies of proterozoic crustal growth and evolution. Dev. Precambrian Geol. 10, 481-508.

Plank, T., Langmuir, C.H., 1998. The chemical composition of subducting sediment and its consequences for the crust and mantle. Chem. Geol. 145, 325-394.

Rea, D.K., Ruff, L.J., 1996. Composition and mass flux of sediment entering the world's subduction zones: implications for global sediment budgets, great earthquakes, and volcanism. Earth Planet. Sci. Lett. 140, 1-12.

Richards, M.A., Yang, W.-S., Baumgardner, J.R., Bunge, H.P., 2001. Role of a low-viscosity zone in stabilizing plate tectonics: implications for comparative terrestrial planetology. Geochem. Geophys. Geosyst. 2. (Paper no. 2000GC000115)

Rosing, M.T., Bird, D.K., Sleep, N.H., Glassley, W., Albarede, F., 2006. The rise of continents - an essay on the geologic consequences of photosynthesis. Paleogeogr., Paleoclimatol., Paleoecol. 232, 99-113.

Scambelluri, M., Tonarini, S., 2012. Boron isotope evidence for shallow fluid across subduction zones by serpentinized mantle. Geology 40 (10), 907-910.

Schneider, R., Weil, W., 2008. Probability and its implications. In: Gani, J., Heyde, C.C., Jagers, P., Kurtz, T.G. (Eds.), Stochastic and Integral Geometry. Springer, Berlin-Heidelberg.

Schubert, G., Turcotte, D.L., Olson, P., 2001. Mantle Convection in Earth and Planets. Cambridge University Press, Cambridge, England.

Schwartzman, D.W., Volk, T., 1989. Biotic enhancement of weathering and the habitability of Earth. Nature 340, 457-460.

Sheng, Y.-M., Zheng, Y.-F., Li, S.-N., Hu, Z., 2013. Element mobility during continental collision: insights from polymineralic metamorphic vein within UHP eclogite in the Dabiie orogen. Metamorph. Geol. 31, 221-241.

Shipley, T.H., Moore, G.F., 1986. Sediment accretion, subduction, and dewatering at the base of the trench slope off Costa Rica: a seismic reflection view of the décollement. J. Geophys. Res. 91 (B2), 2019-2028.

Sleep, N.H., Bird, D.K., Pope, E., 2012. Paleontology of Earth's mantle. Annu. Rev. Earth Planet. Sci. 40, 277-300.

Stern, C.R., 2002. Subduction zones. Rev. Geophys. 40 (4), 1012, http://dx.doi.org/ 10.1029/2001RG000108.

Stern, C.R., 2011. Subduction erosion: rates, mechanisms, and ist role in arc magmatism and the evolution of the continental crust and mantle. Gondwana Res. 20, 284-308.

Stein, C., Hansen, U., 2008. Plate motions and the viscosity structure of the mantle insights from numerical modeling. Earth Planet. Sci. Lett. 272, 29-40.

Tatsumi, Y., Eggins, S., 1995. Subduction Zone Magmatism. Blackwell Scientific, Oxford.

Zhang, G., Kim, J., Dong, H., Sommer, A.J., 2007a. Microbial effects promoting the smectite to illite reaction: role of organic matter interealated in the interlayer. Am. Mineral. 92, 1401-1410.

Zhang, G., Dong, H., Kim, J., Eberl, D.D., 2007b. Microbial reduction of structural $\mathrm{Fe}^{3+}$ in nontronite by a thermophilic bacterium and ist role in promoting the smectite to illite reaction. Am. Mineral. 92, 1411-1419.

Zhang, J., Dong, H., Liu, D., Fischer, T.B., Wang, S., Huang, L., 2012. Microbial reduction of $\mathrm{Fe}(\mathrm{III})$ in illite-smectite minerals by methanogen Methanosarcina mazei. Chem. Geol. 292-293, 35-44. 